\title{
14. Framing dilemmas in the quest for successful crisis management
}

\author{
Allan McConnell
}

\section{Why the cacophony?}

Many science fiction films feature a scene where an alien lands on Earth and is puzzled by the bizarre antics of human beings performing even the simplest of tasks. Perhaps aliens would struggle to make sense of how leaders of the world have responded to the global financial crisis. In the face of arguably the biggest single threat to world stability in recent times, some leaders virtually ignored it (former US President George W. Bush), some said the system was near to collapse (Australian Prime Minister, Kevin Rudd), some said they did not help cause the crisis in any way (Singaporean Prime Minister, Lee Hsien Loong), others said they held a degree of culpability (UK Chancellor, Alistair Darling) and almost everyone started with one position only to take a contrary stance some months later. What is going on? Why have the leaders of the world responded in a multitude of different and constantly changing ways to essentially the same problem?

This puzzle goes to the heart of political science and public policy. As Shapiro and Bedi (2007) suggest, we can see the world as little more than the product of a series of disparate contingencies or we can see it primarily as the operation of certain laws or at least tendencies in political behaviour. Most political science seeks to impose some sense of order on the world to explain patterns of continuity and regularity, as well as change. Hence, we have perspectives such as new institutionalism, rational choice, group and network theory, socioeconomic power and ideational-based models. All attempt to explain the world and its patterns of political behaviour. Many such analyses of the global financial crisis will no doubt emerge in the years to come.

This chapter is not the opportunity to dive into these models and apply them to the global financial crisis. It is, however, an opportunity to put forward a framework that I would argue does help identify a constant amid the diversity and dynamics of framing responses. It is based on the assumption that leaders will always attempt to successfully manage a crisis. It does not claim to be the only constant, or that leadership 'agency' is all powerful, but I consider it to be an important finding that has the potential to be factored into many different policy models. Part of the thinking here is derived from work I have been 
undertaking on policy success in relation to non-crisis issues (Marsh and McConnell forthcoming; McConnell forthcoming). Let me explain further.

\section{Striving for success in crisis management}

Crises present extraordinary challenges for political leaders. Amid threats, uncertainty and urgency, they must undertake a number of tasks, such as making sense of what is going on and articulating its depth and scope to a wider public. I would argue, however, that such tasks are means towards ends, rather than ends in themselves. The goal of leaders is to successfully manage a crisis. After all, who would want to fail, except as an interim measure towards a longer-term success? The focus of this book is 'framing' and therefore we need to ask: if leaders strive to produce frames in order to successfully manage a crisis then what does a 'successful' frame look like from their perspective? The clues are already in Chapters 1 and 2, but I want to draw them out:

- Crisis-management frame for political success: a frame that is intended to ensure political survival and protect or even enhance reputation.

- Crisis-management frame for policy success: a frame that is intended to steer policy down a desired track, whether it be continuity, change or a combination of both.

Of course, it is not possible to get inside the minds of leaders to prove these assumptions. Even interviews have limitations. A large element of crisis leadership is based on instinct rather than a rational appraisal of objectives and all the possible means of achieving them (Flin 1996). Nevertheless, it is a relatively straightforward task to look at the global financial crisis case studies and attribute, with a high degree of plausibility, 'success' motives. For example, in terms of the political game, the initial 'business-as-usual' frame (type-1) of Canadian Prime Minister, Stephen Harper, could be read as an attempt to play down the crisis, while playing up his credentials as an experienced economist who was strongly placed to lead the country at the forthcoming election. This frame suited his quest to hold onto office and enhance his reputation. With regard to the policy game, New Zealand Prime Minister Helen Clark's framing of the crisis as both threat and opportunity (type-2 and type-3) can be read as an attempt to pave the way for policy reform. The fact that an election was looming illustrates that a striving for political success can be contingent on policy success - in this case, the need to demonstrate that the existing Labour-led government was best placed to manage the global financial crisis.

Importantly, no frame is guaranteed to succeed. Some strategies are riskier than others. Risks relate to the likelihood that goals will not be met (Drennan and McConnell 2007). Context is crucial to assessments of risk (Douglas 1992; Althaus 2008). The same activity - walking slowly across the road - is low or even no risk when the road is empty, but high risk if done on a busy motorway. 
Leadership framing of crisis is little different. A frame can be at low risk of failing to achieve 'success' in one context, but that same frame can be high risk in another. We need to think, therefore, about 'context'.

Context can be all manner of phenomena such as culture, time, political mood and economic activity. For the purposes of focusing on framing, I consider context to be the existence or otherwise of strong and credible counter-frames to those articulated by leaders.

If leaders strive for political success by projecting a frame that is intended to ensure their political survival and protect and even enhance their reputation then - all things being equal - a lower risk context is when there is no strong and credible counter-frame in existence. Clearly, this is typically the case in the early sense-making and meaning-making stages of a crisis when leaders need to be out in the public sphere with statements on issues of crisis severity, causes, responsibilities and remedies. Many of the chapters in this volume reveal early attempts to exogenise the global financial crisis and play down its severity (for example, in Canada, the United Kingdom and Ireland), although such frames can survive intact for long periods when there is no credible opposition to produce authoritative counter-frames (for example, in Singapore and to a large extent Canada). When the context is different, however, these same framing strategies can become barriers to political success. It seems clear, for example, that former US President George W. Bush's initial business-as-usual response (playing down the crisis as little more than a market correction) was understandable in terms of his low popularity and a desire to protect his political capital. With corporate failures and increasingly worse economic indicators leading to credible counter-frames, however, his framing became a barrier to achieving his political goals - for example, ending his term in office on a relative 'high' in terms of job approval. His conversion to a type-2 'crisis as threat' frame was a logical move if he was to have any hope of protecting his political reputation and avoiding the label of being chronically 'out of touch' with every major crisis in the United States after 9/11.

A similar logic applies to contexts, risk and the policy game. If leaders strive for policy success by seeking to steer policy down their desired route (stability, reform or a combination) then - all things being equal - a lower risk context is when there is no strong and credible counter-frame. In the United Kingdom, Prime Minister, Gordon Brown, and Chancellor, Alistair Darling, adopted a type-2 'crisis as critical, global threat' frame, a move that was suited to conserving the British policy status quo and, in the political game, circumnavigating questions of the 11-year-old Labour Government's co-responsibility for the occurrence of the crisis. A type-2 frame on its own does not, however, provide the legitimating framework when strong counter-frames are emerging from opponents and the media that policy reforms are needed to tackle a crisis. With 
the Conservative Party ascendant in the polls - though not necessarily pushing a radically different and more popular line on the financial crisis - and the media sceptical towards the government, the move of Brown and Darling to a type- 3 frame becomes understandable. They started presenting the crisis more explicitly as a trigger for regulatory reform. A quest for policy success seems evident in both phases, but frames need to be aligned with goals, otherwise risks of failure are generated.

One might be led to believe, therefore, that crisis framing is a simple task. All that leaders need to do is think about what they want, assess the strength of and support for counter-frames and then opt for the lowest-risk framing strategy with the highest likelihood of political and policy 'success'. As I will explain below, however, leadership is never simple and crisis leadership is doubly complicated.

\section{Hot spots: crisis-framing dilemmas}

After reading the case studies in this volume, it seems evident to me that there are three main 'hot spots' in terms of the leadership challenge of crisis framing. I use the term hot spots to refer to dilemmas of crisis framing that are particularly tough because they put leaders under pressure to perform with decisiveness and conviction at a time when they are being pulled in different directions.

\section{Fast versus successful framing}

Crises shatter our understanding of the world ('t Hart 1993) and create political space that political actors seek to fill rapidly with efforts at meaning making. They present frames designed to tell stakeholders and the general public of what happened and what needs to be done. Crises, however, generate uncertainties (knowledge deficits, ambiguous and contradictory information) that do not lend themselves easily to quick framing that will protect political credibility and guide policy action (or inaction). During crises, leaders seldom have the luxury of picking 'the right time' to offer their accounts, as they normally would. If leaders do not produce credible frames to fill the information and interpretation vacuum triggered by the occurrence of unscheduled events with great speed then others will step in and dominate the discourse.

Crisis-management research has identified various potential leadership pathologies in crises (Boin et al. 2005; Drennan and McConnell 2007). In sense making, for example, leaders can (be led to) misunderstand crucial dimensions of the crisis. Basing their initial public meaning-making efforts on a faulty or incomplete diagnosis of what is going on presents a major risk to leader credibility in a crisis. Despite logic leading us to assume that leaders will initially engage in low-risk framing strategies, they might veer towards high risk through, for example, publicly under-reacting or overreacting. The need to fill a crisis-induced meaning-making vacuum places extraordinary and sometimes unrealistic 
pressures on leaders, who, like anyone else, are confronted with surprising, bewildering, ambiguous, sometimes contradictory signals and expert opinions. Amid all the pressures of crisis management, they might misjudge the accuracy of their own sense making or the persuasiveness of their meaning making.

The latter can occur when they fail to pay enough attention to the evolution of the context in which their frames are being received, interpreted and challenged. Former Spanish Prime Minister José Maria Aznar fell prey to this in the framing contest that developed in relation to the 2004 Madrid bombings. Coming just before general elections, the attack did not just traumatise the nation, it divided it. Aznar's quick and emphatic claim that the attacks were perpetrated by the Spanish State's long-time adversary, the Basque nationalist extremists of ETA, was quickly construed by opposition groups as an opportunistic move to 'cover up' the true causes of the attack - namely, 'payback' by al-Qaeda for Spanish participation in the US-led war in Iraq. The opposition was very effective in dramatising the force of its counter-frame; and it was helped along by a trickle of information from the police investigations into the attacks, which began to point in the direction of Muslim extremists. Aznar persevered regardless and his party paid the price at an election a few days later (Olmeda 2008). Likewise, George W. Bush's initial business-as-usual frame with regard to the financial crisis began to crumble politically as the material realities of the crisis unfolded and lent credence to voices much more pessimistic than Bush's.

\section{Frame consistency versus frame adaptability}

Once leaders espouse a particular crisis frame, subsequent events and their interpretation lead almost inevitably to the emergence of counter-frames. Initial crisis frames rarely stand the test of time. In other words, the context changes and a low-risk frame becomes high risk unless action is taken. This presents leaders with two key challenges: a) to know when the context is changing, and b) to know when the context has altered sufficiently that a new frame really is needed. There is a danger of holding on tightly to an outmoded frame when events and counter-frames lead to a serious questioning of the credibility of the author of the original frame. Canadian Prime Minister Harper's tenacious assertions (type- 1 frame) that the crisis was 'elsewhere' and would have little effect on Canada were discredited when the country slid into recession and his political authority was severely challenged in Parliament.

\section{Framing for political versus policy success}

I have suggested that political leaders always strive for success in two domains: 'politics' and 'policy'. These are often not necessarily complementary, and in crises the tensions between them can become stark. Framing a crisis in order to ensure political survival or enhance political reputation might jar with a framing strategy designed to shape the future direction of policy. Producing a frame that 
satisfies both can be difficult. The Irish Government was fairly quick in settling into a crisis-as-threat frame (type-2) with an element of opportunity emerging later (type-3). These frames were better at providing the foundations for the successful achievement of policy reforms (cuts to pensioner medical benefits, public service reforms and a modernisation of the Irish economy) than they were for shoring up political credibility. Political frames and policy frames do not always go hand in hand. Judging how to blend them while striving for political and policy success can put political leaders under immense pressure.

\section{Conclusion}

Perhaps if the mythical alien came down to Earth, armed with an understanding of how leaders will always strive to ensure political and policy success in response to crisis, it would not be particularly puzzled by the multiple and conflicting leadership responses throughout the world to the global financial crisis. Crises push human beings in all sorts of directions as they struggle to 'succeed' and find their way out. Framing is a way of attempting to succeed in political and policy terms, even though the journey can become rather heated and mistakes can be made along the way.

\section{References}

Althaus, C. 2008, Calculating Political Risk, University of New South Wales Press, Sydney.

Boin, A., 't Hart, P., Stern, E. and Sundelius, B. 2005, The Politics of Crisis Management: Public leadership under pressure, Cambridge University Press, Cambridge.

Douglas, M. 1992, Risk and Blame: Essays in cultural theory, Routledge, London.

Drennan, L. T. and McConnell, A. 2007, Risk and Crisis Management in the Public Sector, Routledge, London.

Flin, R. 1996, Sitting in the Hot Seat: Leaders and teams for critical incident management, John Wiley \& Sons, New York.

't Hart, P. 1993, 'Symbols, rituals and power: the lost dimension in crisis management', Journal of Contingencies and Crisis Management, vol. 1, no. 1 , pp. $36-50$.

Marsh, D. and McConnell, A. (forthcoming), 'Towards a framework for establishing policy success', Public Administration.

McConnell, A. (forthcoming), Understanding Policy Success: Rethinking public policy, Palgrave Macmillan, Basingstoke.

Olmeda, J. 2008, 'A reversal of fortune: blame games and framing contests after the 3/11 terrorist attacks in Madrid', in A. Boin, A. McConnell and P. 't Hart (eds), Governing After Crisis: The politics of investigation, 
accountability and learning, Cambridge University Press, Cambridge, pp. $62-84$.

Shapiro, I. and Bedi, S. 2007, 'Introduction: contingency's challenge to political science', in I. Shapiro and S. Bedi (eds), Political Contingency: Studying the unexpected, the accidental and the unforeseen, New York University Press, New York, pp. 1-18. 